\title{
Avaliação do desempenho energético pelo método prescritivo RTQ-R de uma Unidade Habitacional do Conjunto habitacional Alpha Park em \\ Cacoal-RO
}

Evaluation of energy performance by the RTQ-R prescriptive method of a Housing Unit of the Alpha Park Housing Complex in Cacoal-RO

Evaluación del rendimiento energético por el método prescriptivo RTQ-R de una Unidad de Vivienda del Complejo de Viviendas Alpha Park en Cacoal-RO

Sabrina Demarchi Porto

Acadêmica, FACIMED, Brasil jabrina.d.porto@hotmail.com

Jéssica Andressa Barreira Cazé Acadêmica, FACIMED, Brasil jessica.kze@gmail.com

Fernanda Cavatti Simioni Professora Mestre, FACIMED, Brasil fernanda.simioni@educador.facimed.edu.br 


\title{
Revista Científica ANAP Brasil
}

\author{
ISSN 1984-3240 - Volume 13, número 29, 2020
}

\section{RESUMO}

Para desenvolver habitações sociais mais adequadas e resilientes às condições do ambiente é fundamental considerar o desempenho termo-energético das unidades habitacionais. As propriedades térmicas dos materiais, a região bioclimática onde estas são inseridas e a implantação são características fundamentais para a otimização do desempenho. Desta forma, esta pesquisa tem como objetivo averiguar o desempenho das edificações sociais do bairro Alpha Park II, no município de Cacoal - RO. O método prescritivo Regulamento Técnico da Qualidade para o Nível de Eficiência Energética de Edificações Residenciais - RTQ-R, utilizado para determinar o nível de eficiência alcançado pelas unidades pertencentes ao Programa governamental Minha Casa Minha Vida. Com a análise foi possível observar que independente da implantação da UH, a classificação final não foi influenciada, no entanto, foi possível observar que os ambientes de permanência prolongada podem obter um nível de eficiência maior, de acordo com a implantação no terreno. Logo, compreende-se que para que as habitações populares obtenham maior conforto ambiental e melhor desempenho energético em zonas bioclimáticas como a ZB8, que possui uma grande quantidade de graus-horas, será necessário além do estudo de implantação, o investimento em materiais com características térmicas melhores, além de oferecer subsídios para sistemas passivos de refrigeração.

PALAVRAS-CHAVE: Qualidade do ambiente. Conforto térmico. Habitações populares.

\section{SUMMARY}

In order to develop social housing that is more appropriate and resilient to environmental conditions, it is essential to consider the thermo-energetic performance of housing units. The thermal properties of the materials, the bioclimatic region where they are inserted and the implantation are fundamental characteristics for performance optimization. Thus, this research aims to investigate the performance of the social buildings of the Neighborhood Alpha Park II, in the municipality of Cacoal - RO. The prescriptive method Technical Quality Regulation for the Level of Energy Efficiency of Residential Buildings - RTQ-R, used to determine the level of efficiency achieved by the units belonging to the government program My House My Life. With the analysis it was possible to observe that regardless of the implementation of the UH, the final classification was not influenced, however, it was possible to observe that the environments of prolonged permanence can obtain a higher level of efficiency, according to the deployment on the ground. Therefore, it is understood that for popular housing to obtain greater environmental comfort and better energy performance in bioclimatic zones such as $Z B 8$, which has a large amount of degree-hours, it will be necessary in addition to the implementation study, investment in materials with better thermal characteristics, in addition to offering subsidies for passive refrigeration systems.

KEYWORDS: Quality of the environment. Thermal comfort. Popular housing.

\section{RESUMEN}

Con el fin de desarrollar viviendas sociales más apropiadas y resistentes a las condiciones ambientales, es esencial considerar el rendimiento termoenergético de las unidades de vivienda. Las propiedades térmicas de los materiales, la región bioclimática donde se insertan y la implantación son características fundamentales para la optimización del rendimiento. Por lo tanto, esta investigación tiene como objetivo investigar el desempeño de los edificios sociales del Barrio Alpha Park II, en el municipio de Cacoal - RO. El método prescriptivo Regulación técnica de calidad para el nivel de eficiencia energética de los edificios residenciales - RTQ- $R$, utilizado para determinar el nivel de eficiencia alcanzado por las unidades pertenecientes al programa de gobierno Mi Casa Mi Vida. Con el análisis se pudo observar que, independientemente de la aplicación de la $\mathrm{UH}$, la clasificación final no se vio influenciada, sin embargo, fue posible observar que los entornos de permanencia prolongada pueden obtener un mayor nivel de eficiencia, según el despliegue sobre el terreno. Por lo tanto, se entiende que para que la vivienda popular obtenga un mayor confort ambiental y un mejor rendimiento energético en zonas bioclimáticas como ZB8, que tiene una gran cantidad de gradohora, será necesario además del estudio de implementación, inversión en materiales con mejores características térmicas, además de ofrecer subvenciones para sistemas de refrigeración pasiva.

PALABRAS CLAVE: Calidad del entorno. Confort térmico. Vivienda popular. 


\section{Revista Científica ANAP Brasil}

ISSN 1984-3240 - Volume 13, número 29, 2020

\section{INTRODUÇÃO}

A arquitetura é um dos grandes contribuintes para o desenvolvimento sustentável, e sua aplicação em edificações de grande influência na sociedade, como por exemplo habitações de interesse social, além de preservar o meio ambiente, poderá conscientizar, promover e impulsionar as práticas sustentáveis tanto para os residentes locais quanto para a comunidade do entorno das edificações.

A habitação é, para o ser humano, o seu espaço essencial, que envolve o elemento físico da moradia e a qualidade ambiental do espaço construído. Para a obtenção dessa qualidade e no âmbito residencial, é necessário adotar estratégias que promovam o conforto térmico e lumínico, reduzindo a utilização dos mecanismos artificiais. Porém, a partir da Revolução Industrial e do desenvolvimento tecnológico, a utilização destes mecanismos artificiais passou a ser mais frequentes devido a facilidade de aplicação (BRASIL, 2011).

Para desenvolver edificações mais adequadas e resilientes às condições do ambiente, é fundamental que se considerem as variáveis bioclimáticas e as propriedades térmicas dos materiais, trabalhando-as conjuntamente. A adaptabilidade ao clima local e a ventilação e iluminação natural, devem ser levadas em consideração para promover as melhores condições de conforto aos usuários. Além disso, a aplicação de estratégias passivas melhora o desempenho das edificações, promovendo condições de conforto com menor uso de medidas ativas para iluminação, aquecimento ou refrigeração. Com isso é possível reduzir custos de manutenção, de consumo de eletricidade e causar menor impacto ao meio ambiente (LAMBERTS, DUTRA, PEREIRA, 2014).

Com o objetivo de avaliar o desempenho e eficiência energética de habitações de interesse social, o governo federal lançou em 2012 o manual para aplicação do Regulamento Técnico da Qualidade para Edificações Residenciais (RTQ-R). Este regulamento estabelece alguns critérios de desempenho da envoltória, onde classifica a edificação entre os níveis de $A$ (adequado) a $E$ (insatisfatório), a partir de dois métodos, o prescritivo e o de simulação.

O método prescritivo consiste na avaliação da envoltória da edificação a partir da coleta de dados sobre os materiais utilizados na construção, a análise da orientação solar, a quantidade e percentual de aberturas tanto para iluminação quanto para ventilação natural, e com isso, é aplicado equações que variam de acordo com a zona bioclimática onde a edificação está inserida. Já no método de simulação, é utilizado um software de simulação termo-energético e determinado através da análise o desempenho da habitação.

\section{OBJETIVOS}

Com base nesta visão busca-se comparar o nível de eficiência energética das implantações de uma habitação de interesse social unifamiliar do Conjunto Habitacional Alpha Park II, no município de Cacoal-RO.

\section{METODOLOGIA}

Para a análise do desempenho energético foi aplicado o método prescritivo do RTQ-R. Este consiste no levantamento in loco de dados necessários para a obtenção do resultado final do 


\title{
Revista Científica ANAP Brasil
}

\author{
ISSN 1984-3240 - Volume 13, número 29, 2020
}

nível de eficiência energética. Após a coleta das informações necessárias, é preenchido o formulário em Excel com as características relevantes da UH, sendo estas: as dimensões dos ambientes (largura, comprimento e pé direito); a implantação no terreno quanto a orientação solar; envoltória; características das aberturas, como áreas efetivas de iluminação e ventilação, tipo de abertura, locação na planta e peitoril; e materiais utilizados, que compõem as paredes, coberturas, pisos, além das cores externas e as espessuras das camadas (MANUAL RTQ-R, 2012).

\subsection{Caracterização do Objeto De Estudo}

A unidade escolhida para a avaliação foi o conjunto habitacional Alpha Park II, e essa escolha foi feita com o objetivo de avaliar e representar a qualidade das habitações sociais entregues pelo Programa Federal Minha Casa Minha Vida. A localização da unidade no estado de Rondônia a classifica na Zona Bioclimática 8 conforme NBR 15220 (ABNT, 2003) conforme mapa de zoneamento, Figura 1.

O clima do estado, bem como, praticamente toda a região Norte, é caracterizado como equatorial, ou seja, quente e úmido durante maior parte do ano.

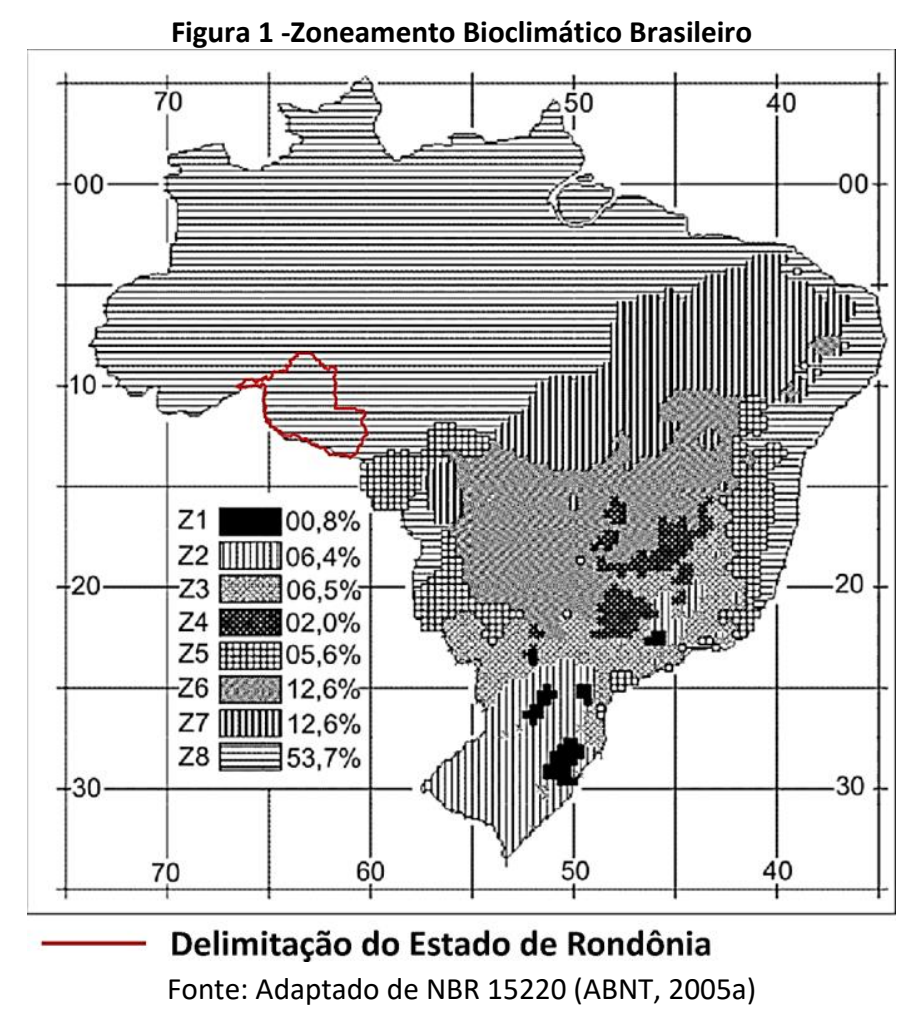

A unidade escolhida representa a tipologia aplicada em todo o conjunto habitacional, sendo caracterizada como baixo padrão, e contém sala, cozinha, dois quartos e um banheiro. A comparação foi realizada através da modificação na implantação das unidades. A implantação padrão das UHs no conjunto habitacional é Norte/Sul, com a fachada principal para Sul, Figura 2. 
Revista Científica ANAP Brasil

ISSN 1984-3240 - Volume 13, número 29, 2020

Figura 2 - Planta padrão com a fachada principal para o Sul

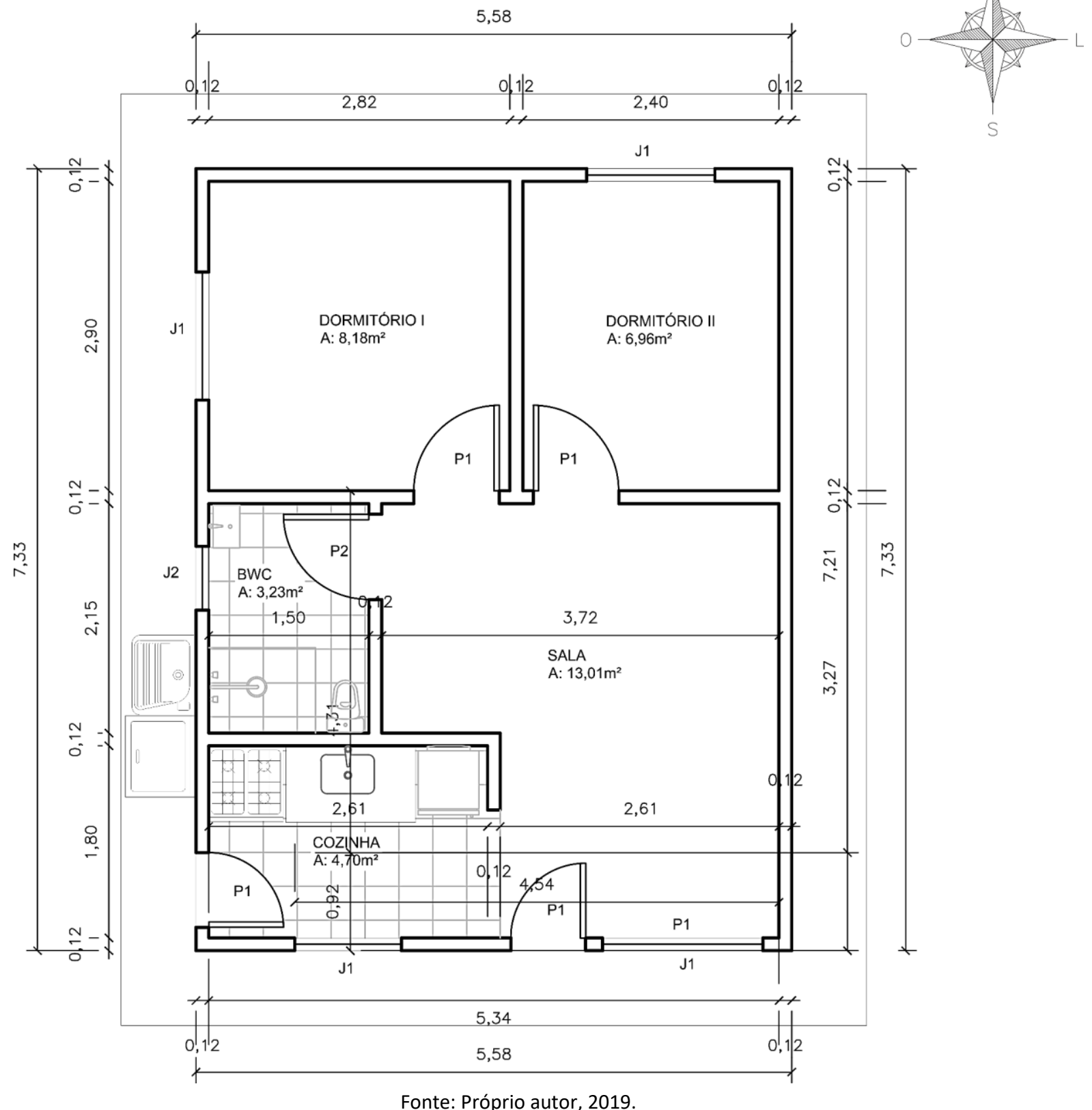

Seu programa de necessidades é composto área construída de 40,90m². No Quadro 1 estão descritas as características quanto ao tipo de vedação vertical interna e externa, cobertura, forro, esquadrias e aquecimento de água. 


\section{Revista Científica ANAP Brasil}

\section{ISSN 1984-3240 - Volume 13, número 29, 2020}

Quadro 1 - Características da unidade habitacional

\begin{tabular}{|l|l|}
\hline Área Total & $40,90 \mathrm{~m}^{2}$ \\
\hline Área Útil & $36,08 \mathrm{~m}^{2}$ \\
\hline Fundação & Radier \\
\hline Inserção no Lote e Orientação Solar & Fachada Frontal Sul, com as janelas dos quartos voltadas para norte e oeste. \\
\hline Vedações Verticais Externas & $\begin{array}{l}\text { Paredes com vedação de tijolos } 6 \text { furos quadrados, assentados na menor } \\
\text { dimensão, dimensões do tijolo: } 9,0 \times 14,0 \times 19,0 \mathrm{~cm} \text {, espessura da argamassa } \\
\text { de assentamento: } 1,0 \mathrm{~cm}, \text { espessura da argamassa de emboço: } 2,5 \mathrm{~cm}, \\
\text { espessura total da parede: } 14,0 \mathrm{~cm} .\end{array}$ \\
\hline Vedações Verticais Internas & $\begin{array}{l}\text { Paredes com vedação de tijolos } 6 \text { furos quadrados, assentados na menor } \\
\text { dimensão, dimensões do tijolo: } 9,0 \times 14,0 \times 19,0 \mathrm{~cm} \text {, espessura da argamassa } \\
\text { de assentamento: } 1,0 \mathrm{~cm}, \text { espessura da argamassa de emboço: } 2,5 \mathrm{~cm}, \\
\text { espessura total da parede: } 14,0 \mathrm{~cm} .\end{array}$ \\
\hline Esquadrias & Em alumínio \\
\hline Forro & PVC \\
\hline Cobertura & Telha cerâmica \\
\hline Inclinação da Cobertura & $30 \%$ \\
\hline Abastecimento de Água & Abastecimento público. \\
\hline Reservatório & $200 \mathrm{~L}$ \\
\hline Consumo & $144 \mathrm{~L} /$ dia \\
\hline
\end{tabular}

Fonte: Próprio autor, 2019.

O Catálogo de Propriedades Térmicas de Paredes, Coberturas e Vidros (INMETRO, 2013) foi a principal fonte de dados da transmitância térmica $(U)$ e a capacidade térmica $(\mathrm{CT})$ dos sistemas construtivos adotados. Os valores em questão podem ser observados nas Figuras 3 e 4 .

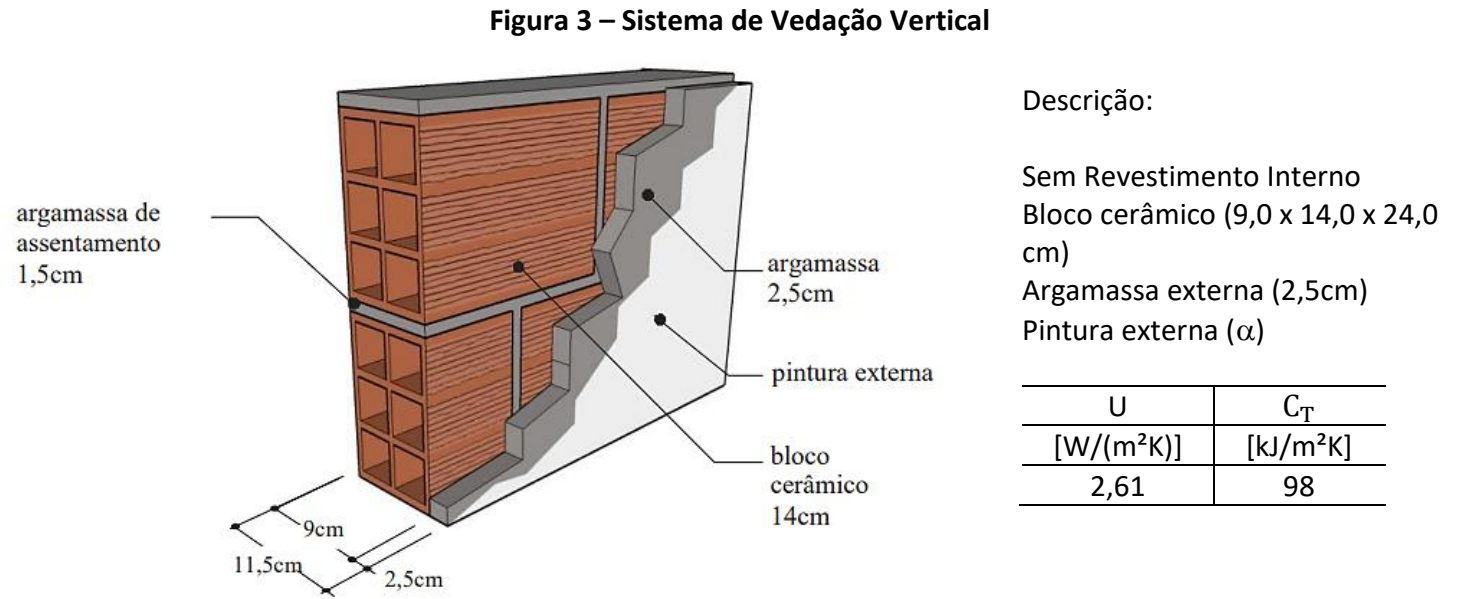

Fonte: Adaptado de INMETRO, 2013. 


\section{Revista Científica ANAP Brasil}

\section{ISSN 1984-3240 - Volume 13, número 29, 2020}

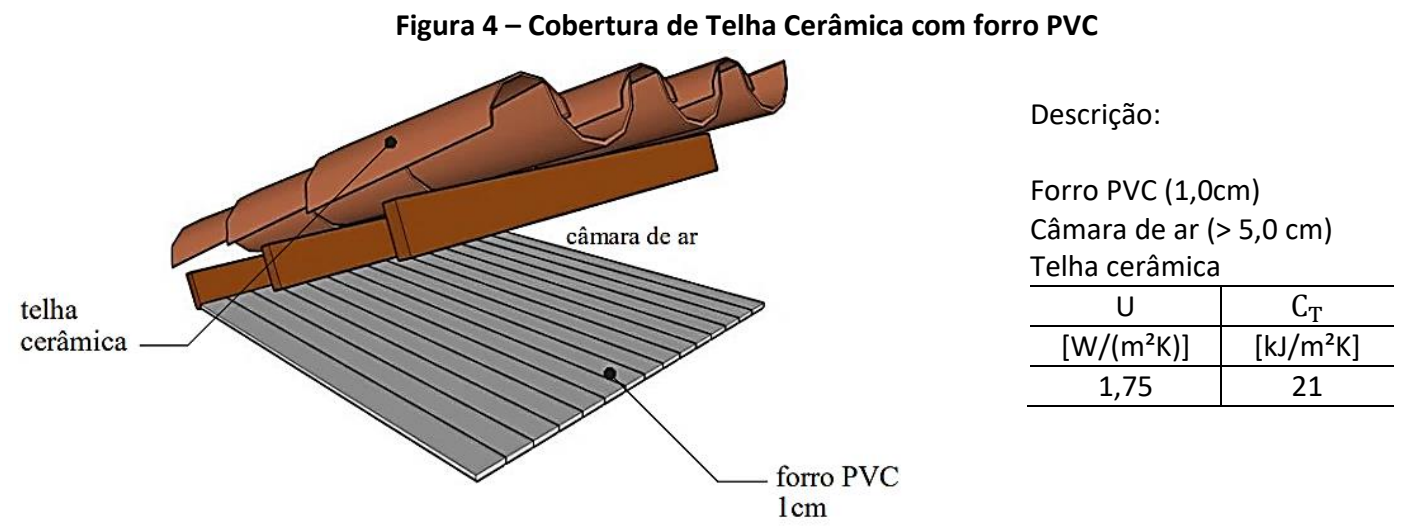

Fonte: Adaptado de INMETRO, 2013.

Na Tabela 1 está representada as áreas das paredes externas e aberturas dos ambientes de permanência prolongada.

Tabela 1 - Áreas das paredes na implantação modelo

\begin{tabular}{|c|c|c|c|c|c|c|c|}
\hline \multicolumn{8}{|c|}{ AMBIENTES DE PERMANÊNCIA PROLONGADA } \\
\hline Ambiente & $\begin{array}{l}\text { Área } \\
\text { Total } \\
\left(\mathrm{m}^{2}\right)\end{array}$ & $\begin{array}{l}\text { Pé direito } \\
(\mathrm{m})\end{array}$ & Orientação & $\begin{array}{c}\text { Medida de } \\
\text { paredes } \\
\text { externas (m) }\end{array}$ & $\begin{array}{c}\text { Área de } \\
\text { Paredes } \\
\text { externas }\left(\mathrm{m}^{2}\right)\end{array}$ & $\begin{array}{c}\text { Área das } \\
\text { aberturas } \\
\left(\mathrm{m}^{2}\right)\end{array}$ & $\begin{array}{l}\text { Área final das } \\
\text { paredes }\left(\mathrm{m}^{2}\right)\end{array}$ \\
\hline \multirow{2}{*}{ Dormitório I } & \multirow{2}{*}{8,18} & \multirow{2}{*}{3,00} & Parede Norte & 3,00 & 9,00 & - & 9,00 \\
\hline & & & Parede Oeste & 3,08 & 9,24 & 1,20 & 8,04 \\
\hline \multirow{2}{*}{ Dormitório II } & \multirow{2}{*}{6,96} & \multirow{2}{*}{3,00} & Parede Norte & 2,58 & 7,74 & 1,20 & 6,54 \\
\hline & & & Parede Leste & 3,08 & 9,24 & - & 9,24 \\
\hline \multirow{2}{*}{ Sala de Estar } & \multirow{2}{*}{13,01} & \multirow{2}{*}{3,00} & Parede Sul & 2,73 & 8,19 & 2,88 & 5,31 \\
\hline & & & Parede Leste & 4,25 & 12,75 & - & 12,75 \\
\hline
\end{tabular}

Fonte: Próprio autor, 2020.

Os pré-requisitos adotados sobre iluminação e ventilação natural, levam em consideração os coeficientes de área efetiva tanto para iluminação, quanto para ventilação, sendo necessário excluir as áreas de caixilhos das janelas, bem como analisar o tipo de abertura para calcular a porcentagem de ventilação no ambiente. Os valores das áreas efetivas de iluminação e ventilação da residência em análise podem ser observados na Tabela 2.

Tabela 2 - Dimensões e áreas efetivas de ventilação e iluminação das janelas

\begin{tabular}{c|c|c|c|c|c|c|c}
\hline Ambiente & $\begin{array}{c}\text { Área do } \\
\text { Ambiente } \\
\left(\mathbf{m}^{\mathbf{2}}\right)\end{array}$ & $\begin{array}{c}\text { Largura } \\
\text { Janela } \\
(\mathbf{m})\end{array}$ & $\begin{array}{c}\text { Altura } \\
\text { Janela }(\mathbf{m})\end{array}$ & $\begin{array}{c}\text { Área efetiva da } \\
\text { Janela }\left(\mathbf{m}^{2}\right)\end{array}$ & $\begin{array}{c}\text { Fator de } \\
\text { Sombreamento }\end{array}$ & $\begin{array}{c}\text { Fator de } \\
\text { Ventilação }\end{array}$ & Tipo de Janela \\
\hline Dormitório I & 8,18 & 1,20 & 1,00 & 0,90 & 1,0 & 0,45 & $\begin{array}{c}2 \text { Folhas (1 } \\
\text { fixa, } 1 \text { móvel) }\end{array}$ \\
\hline Dormitório II & 6,96 & 1,20 & 1,00 & 0,90 & 1,0 & 0,45 & $\begin{array}{c}2 \text { Folhas (1 } \\
\text { fixa, } 1 \text { móvel) }\end{array}$ \\
\hline Sala de Estar & 13,01 & 1,20 & 1,00 & 0,90 & 1,0 & 0,45 & $\begin{array}{c}2 \text { Folhas (1 } \\
\text { fixa, } 1 \text { móvel) }\end{array}$ \\
\hline
\end{tabular}

Após levantar todos os dados e características da unidade habitacional, é necessário fazer o preenchimento da planilha RTQ-R, que consiste nas seguintes etapas:

a) Pré-requisitos dos ambientes 


\section{Revista Científica ANAP Brasil}
b) Pré-requisitos da UH
c) Bonificações
d) Aquecimento de água

Na residência há a presença de um sistema de aquecimento de água, e os dados relevantes a esse sistema foram preenchidos na planilha para obtenção da nota. Com a conclusão da planilha é gerada a classificação energética da edificação. A nota final é a soma de todas as notas obtidas nos cálculos anteriores, com ela é possível classificar o nível de eficiência energética da edificação.

\subsection{ESTUDO DE IMPLANTAÇÃO}

A implantação original foi utilizada como parâmetro para a comparação entre as demais implantações. Com a fachada principal voltada para o Sul foi realizado o estudo solar e dos ventos dominantes, conforme Figura 5 . As somas das aberturas em cada fachada estão descritas na Tabela 3.

Figura 5 - Implantação padrão do conjunto

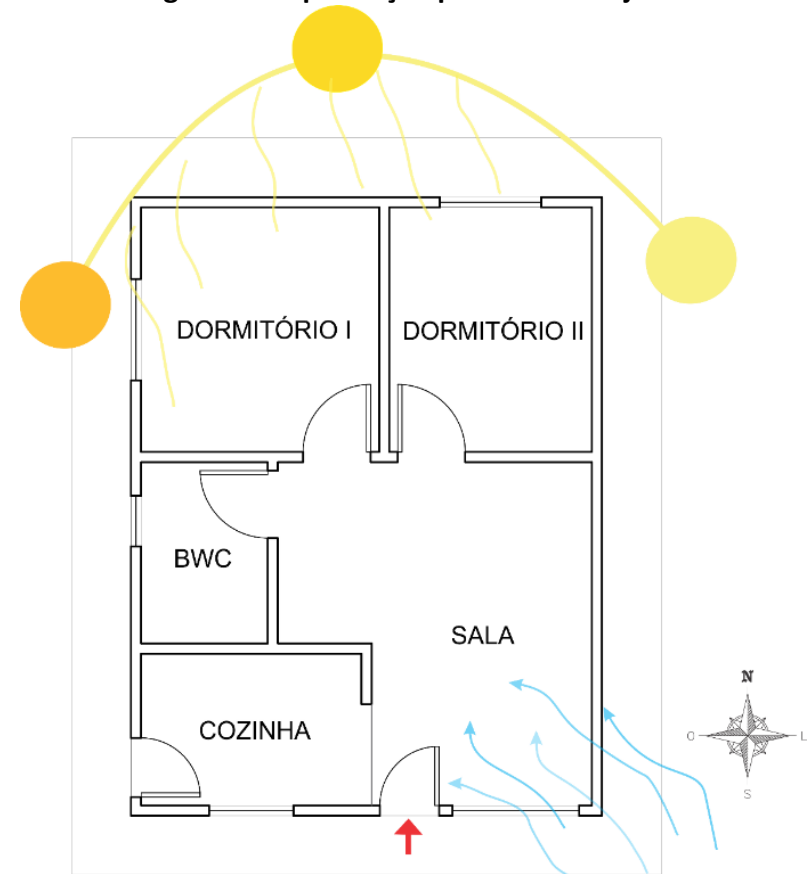

Fonte: Próprio autor, 2020.

Tabela 3 - Áreas de aberturas da fachada Sul

\begin{tabular}{|l|c|c|}
\hline \multicolumn{1}{|c|}{ Orientação } & Ambiente & Área de Abertura $\left(\mathbf{m}^{\mathbf{2}}\right)$ \\
\hline Fachada Norte & Quarto 2 & 1,20 \\
\hline Fachada Sul & Sala/ Cozinha & 2,88 \\
\hline Fachada Leste & - & - \\
\hline Fachada Oeste & Cozinha/ Bwc/ Quarto 1 & 3,12 \\
\hline
\end{tabular}




\section{Revista Científica ANAP Brasil}

\section{ISSN 1984-3240 - Volume 13, número 29, 2020}

Para que fosse possível averiguar o desempenho de cada implantação, foram analisadas as implantações Norte, Leste e Oeste, conforme a Figura 6, 7 e 8 respectivamente, permanecendo as dimensões das aberturas de acordo com a orientação destas, pode-se observar na Tabela 4.

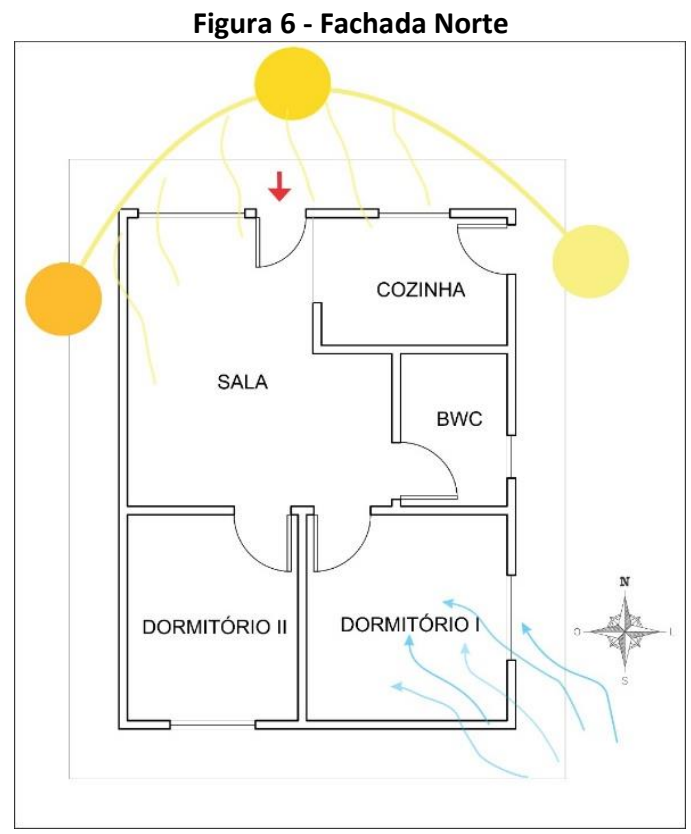

Fonte: próprio autor, 2020.

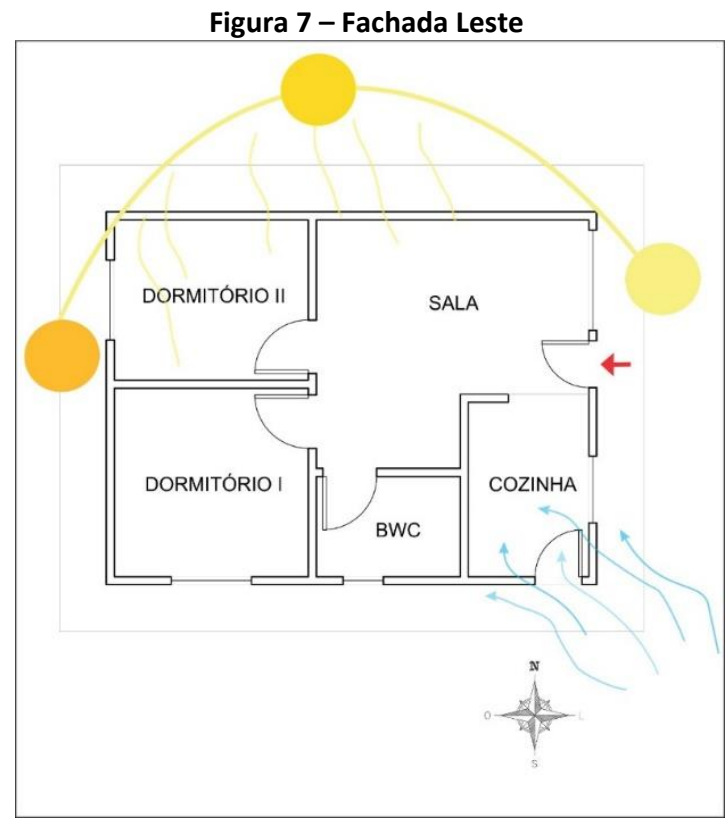

Fonte: próprio autor, 2020. 
Revista Científica ANAP Brasil

ISSN 1984-3240 - Volume 13, número 29, 2020

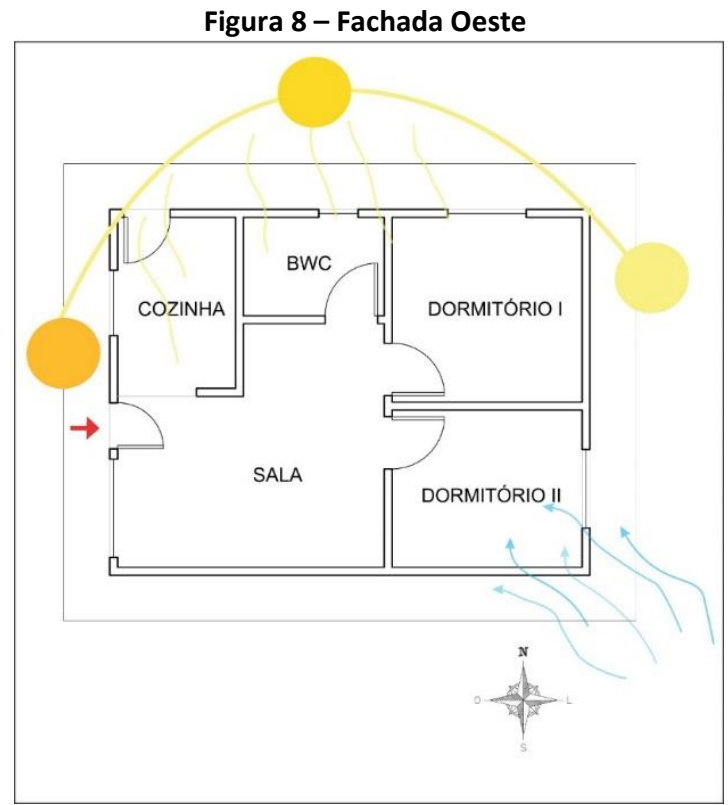

Fonte: próprio autor, 2020.

Tabela 4 - Áreas de aberturas das implantações

\begin{tabular}{|c|c|c|c|}
\hline Fachada Principal & Orientação & Ambiente & Área de Abertura $\left(\mathrm{m}^{2}\right)$ \\
\hline \multirow{4}{*}{ Norte } & Fachada Norte & Sala/Cozinha & 2,88 \\
\hline & Fachada Sul & Dormitório II & 1,20 \\
\hline & Fachada Leste & Cozinha/ Bwc/ Dormitório I & 3,12 \\
\hline & Fachada Oeste & - & - \\
\hline \multirow{4}{*}{ Leste } & Fachada Norte & - & - \\
\hline & Fachada Sul & Cozinha/ Bwc/ Dormitório I & 3,12 \\
\hline & Fachada Leste & Sala/ Cozinha & 2,88 \\
\hline & Fachada Oeste & Dormitório II & 1,20 \\
\hline \multirow{4}{*}{ Oeste } & Fachada Norte & Cozinha/ Bwc/ Dormitório I & 3,12 \\
\hline & Fachada Sul & - & - \\
\hline & Fachada Leste & Dormitório II & 1,20 \\
\hline & Fachada Oeste & Sala/ Cozinha & 2,88 \\
\hline
\end{tabular}

Fonte: próprio autor, 2020.

\section{RESULTADOS}

Após a coleta dos dados e o preenchimento da planilha, foi possível simular a eficiência energética alcançada pela edificação nas quatro implantações. A pontuação alcançada pela unidade habitacional está descrita no Quadro 2. 


\section{Revista Científica ANAP Brasil}

ISSN 1984-3240 - Volume 13, número 29, 2020

Quadro 2 - Relatório Final RTQ-R

\begin{tabular}{|l|c|}
\hline \multicolumn{1}{|c|}{ Identificação } & Classificação final da UH \\
\hline Implantação Sul & C \\
\hline Implantação Norte & C \\
\hline Implantação Leste & C \\
\hline Implantação Oeste & C \\
\hline \multicolumn{2}{|l|}{} \\
\hline
\end{tabular}

Fonte: próprio autor, 2019, adaptado de RTQ-R.

Nos resultados foi percebido a uniformidade na classificação, independentemente de sua implantação. Desta forma, o resultado C, foi alcançado. No Tabela 5, pode ser observado os valores atribuídos para cada requisito da planilha RTQ-R quanto à implantação sul, o mesmo resultado se repete as demais implantações.

Tabela 5 - Relatório Final RTQ-R

\begin{tabular}{l|c|c}
\hline \multicolumn{2}{c}{ PONTUAÇÃO TOTAL } \\
\hline Identificação & Classificação & Valor obtido \\
\hline Envoltória para Verão & C & 3,00 \\
\hline Envoltória para Inverno & Não se aplica & - \\
\hline Aquecimento de Água & $\mathrm{A}$ & 5,00 \\
\hline Equivalente numérico da envoltória & $\mathrm{C}$ & 3,00 \\
\hline Envoltória se refrigerada artificialmente & $\mathrm{D}$ & 2,00 \\
\hline Bonificações & - & 0,28 \\
\hline Região & Norte & - \\
\hline Coeficiente a & - & 0,95 \\
\hline \multicolumn{2}{c}{ Classificação final da UH } \\
\hline
\end{tabular}

Fonte: próprio autor, 2020, adaptado de RTQ-R.

A Tabela mostra que a eficiência energética da edificação não obteve um resultado satisfatório quanto a envoltória para verão, equivalente numérico e refrigeração artificial. No entanto, o sistema de aquecimento de água obteve classificação $A$. O que influencia para o resultado $C$ na classificação final da unidade habitacional. Quando analisado os resultados dos Graus-horas para resfriamento, foi possível observar um comportamento diferente quanto a classificação, segue Quadro 3.

\begin{tabular}{l} 
Quadro 3 - Classificação de Graus-Hora de Resfriamento (GHr) \\
\begin{tabular}{|l|c|c|c|c|}
\hline Identificação & $\begin{array}{c}\text { Implantação } \\
\text { Sul }\end{array}$ & $\begin{array}{c}\text { Implantação } \\
\text { Norte }\end{array}$ & $\begin{array}{c}\text { Implantação } \\
\text { Leste }\end{array}$ & $\begin{array}{c}\text { Implantação } \\
\text { Oeste }\end{array}$ \\
\hline Dormitório I & C & B & C & B \\
\hline Dormitório II & C & B & B & C \\
\hline Sala & B & C & C & C \\
\hline
\end{tabular} \\
\hline
\end{tabular}

Com relação a orientação padrão (sul), as aberturas dos dormitórios estão predominantemente voltadas para o norte, influenciando a sua classificação. Neste cenário, apenas a sala, que está implantada na fachada sul, obtém um resultado satisfatório. Na fachada norte, com as aberturas dos dormitórios voltados para sul, o resultado B foi obtido em ambos ambientes, o que demostra que apesar do resultado final ter sido C, o estudo da orientação solar na implantação da edificação pode influenciar positivamente no conforto termo-energético das áreas de repouso. Quanto à implantação Leste e Oeste ambas obtiveram resultados similares, 


\title{
Revista Científica ANAP Brasil
}

\author{
ISSN 1984-3240 - Volume 13, número 29, 2020
}

prevalecendo a eficiência em apenas um dos dormitórios, influenciados pela orientação norte/sul.

Os Graus-horas de resfriamento foi o fator principal para não alcançar uma eficiência. Como pode ser observado, o equivalente numérico da envoltória, sendo este referente a envoltória, materiais e o sombreamento das aberturas na edificação, não foi capaz de suprir as necessidades e pré-requisitos para a zona bioclimática inserida. Com isso, a edificação, independentemente de sua inserção, não conseguiu alcançar uma classificação satisfatória.

\section{CONCLUSÃO}

Conforme as informações apresentadas nesta pesquisa foi possível simular a eficiência energética alcançada pela edificação, localizada em Cacoal-RO. Visto que a mesma obteve a classificação final "C". De acordo com os dados obtidos, a edificação obteve baixa pontuação devido a necessidade de refrigeração artificial ou a utilização de estratégias passivas de resfriamento. Os resultados demostrados neste estudo mostram que para garantir uma habitação de interesse social com as qualidades mínimas de conforto ambiental e eficiência energética para seus usuários, deve-se projetar estudando o desempenho dos materiais e as características das zonas bioclimáticas onde as UH serão implantadas.

\section{AGRADECIMENTO}

Os autores agradecem à Faculdade de Ciências Biológicas de Cacoal - RO que por meio do Programa de Incentivo à Iniciação Cientifica (PIIC) tornou possível a realização desta pesquisa.

\section{REFERÊNCIAS BIBLIOGRÁFICAS}

ASSOCIAÇÃO BRASILEIRA DE NORMAS TÉCNICAS (ABNT) - NBR 15220-3 Desempenho térmico de edificações - Parte 3: Zoneamento bioclimático brasileiro e diretrizes construtivas para habitações unifamiliares de interesse social. Rio de Janeiro, 2005.

ASSOCIAÇÃO BRASILEIRA DE NORMAS TÉCNICAS (ABNT) - NBR 15575-1 Edificações habitacionais - Desempenho Parte 1: Requisitos Gerais. Rio de Janeiro, 2013.

BRASIL, Lei n. 10295 de 17 de outubro de 2011. Dispõe sobre a Política Nacional de Conservação e Uso Racional de Energia e dá outras providências. Lex: Diário Oficial da União, Brasília, 2001a.

Catálago de Propriedades térmicas de paredes, coberturas e vidros- Anexo V. INMETRO, Portara no 50/2013.

MANUAL para Aplicação do RTQ-R: Manual RTQ-R 4.2. [S. I.]: Eletrobras/Procel, 2012.

LAMBERTS, Roberto; DUTRA, Luciano; PEREIRA, Fernando O. R. Eficiência energética na arquitetura. 3 ed. Rio de Janeiro: Eletrobras/Procel, 2014. Disponível em: <www.mme.gov.br/documents/10584/19855241/Livro\%20\%20Eficiência\%20Energética\%20na\%20Arquitetura.pdf>. Acesso em: 06 de nov. de 2019. 